\title{
Moving from a Culture of Punishment to one of Understanding in English Secondary Schools
}

\author{
Sara von Sommaruga, MSc
}

Dialogue Therapeutic Service, Secondary Schools and Private Practise in GP Surgery, Sussex, England

\author{
Doi:10.5901/jesr.2014.v4n2p96
}

\begin{abstract}
This paper describes the challenges encountered in managing and developing counselling services in two English Secondary schools over the last ten years. During this time schools in England have undergone enormous change, partly initiated by the economic crisis and also by new educational legislation being implemented by a non-ministerial government department for Her Majesties Chief Inspectors of schools in England (Ofsted). Teachers struggling with the changes, feel under enormous pressure to deliver high academic results with very little space left over for thinking about and supporting the more challenging students. Pressure and stress has grown and as a way of trying to manage in this difficult situation, teachers have taken up an authoritarian role that has generated a more punishing culture. The result is that students in trouble receive negative attention instead of being given understanding and support resulting in many of them being excluded from school. Support for these students within this, sometimes, unsympathetic context is provided by the counselling service, which tends to be used as a place to dump students who cannot be managed in the classroom. With so many young people being referred for help, a trainee counsellor's clinical placement programme was introduced to increase the availability of counselling support. A more thoughtful and child centred culture in both schools was generated with the help of the counselling service so that staff teams could begin to think collaboratively about each child's emotional, behavioural and social needs to support them to stay in school to achieve their full academic potential and have a successful future.
\end{abstract}

\section{Introduction}

The source of this paper came from work carried out by the author in three different secondary schools in England. This included conducting individual and group counselling, managing counselling services, working with multidisciplinary teams, co-ordinating an Inclusion Panel, collaborating with teachers and supervising and training trainee counsellors. This focus is on schools with students who have emotional, behavioural and social difficulties that interfere with their learning. They are at risk of under-achieving, being excluded and having possible future mental health difficulties.

Facilitating change in schools and enabling students to engage in education is best achieved by valuing the importance of their relationships and supporting teachers and students to think differently. These students spend so much of their lives within the educational context, it is important to them. So, rather than punishing and excluding, teachers learn to translate what is going on for them to understanding their behaviour as a communication about their distress.

\section{Ongoing change in the schools}

Facing the on-going task of trying to manage the changes initiated by the economic crisis and Ofsted has put teachers under enormous pressure to deliver high academic results and to keep every child in education. If a child has special needs the school is responsible for putting special support in place. This is sometimes just a box ticking exercise. Families are handing their children over to schools with the expectation that they no longer need to take responsibility.

In England every child is required to be in education until the age of 18. Schools are constantly assessing, measuring and monitoring teachers and students. Teachers' workload has increased. They work longer hours. Their salaries have been frozen and strikes are more regular.

\section{Effect on Teachers, Students and their Families}

Teachers say they feel stressed, devalued, unsupported and demoralised. They are also frustrated by the educational system because it has moved too far towards academic attainment and too far away from thinking about how to bring up 
happy and confident children who feel hopeful about the future. Schools report an increase in families experiencing economic and social difficulties brought on by the economic crisis. In some families both parents are working longer hours and spending less time as a family to talk and share. Children report that they do not feel able to talk to their families about how they are feeling because they do not want to upset them or add to their stress. Families are ringing the school to share the stresses and strains of family life and their anxieties about their children.

\section{Introduction of Counselling Services into Schools}

Counselling services were introduced into all three schools because of an increase in students presenting with serious emotional, behavioural and social problems. These presenting problems included being on the verge of permanent exclusion, exhibiting challenging behaviour, refusing school, breaking the rules and pushing boundaries, not engaging in education and many other complex family issues. These were acting as barriers to learning and developing healthy relationships. Teachers said they did not have the time, knowledge or skills to support these students.

Providing a counselling service can also sometimes create an unconscious idea or wish in schools that it is possible to make students all better in an instant and return them to their teachers, cured and ready to behave and learn. The counselling service was at times used as a place to dump these more challenging and difficult students whom they were unable to manage. Like individuals, schools develop defences against difficult emotions, which are too threatening or painful to acknowledge and some times project them in to students and or counselling services. These emotions may be a response to the strain of the economic crisis and Ofsted's change of policy (Obholzer\&Roberts 1994). When counsellors try to discuss a student's progress with teachers they would often struggle to hear or understand how the student was feeling. It is possible that these teachers felt they had failed the student by referring them to counselling and then felt competitive when the counsellor shared a student's positive progress.

\section{Earlier Project to include 'Hard to Reach Students in Education'}

In 2005 while working in a large comprehensive secondary school in London a project was set up by the author and funded by Wandsworth Council for students aged between 14-15, who were identified by the school as not engaging in education and training (NEET). These students were at risk of being permanently excluded and leaving school without qualifications.

Teachers were very concerned about this group of students and did not know how to help them. The students continuously pushed the boundaries and truanted from school. There were an increasing number of incident reports, exclusions and challenging behaviour, breaking the law, displaying confrontational and angry behaviour towards teachers and a total disregard for authority and rules. Teachers discovered that no amount of punishment made any difference to their behaviour.

This was the start of beginning to think with teachers, what might be needed in order to be able to understand these students so that they could stay in in school and fulfil their potential and have a successful future. It was also the first time that the counselling service had introduced the idea into the school about working collaboratively with the teachers, meeting regularly and thinking together about each student's individual needs, rather than punish and exclude them.

The project identified that in order to understand these students it would be imperative to help the students to talk about their family life, which can affect their school life. Families are children's first experience of relationships; they learn from their primary caregivers how to regulate their emotions and behaviour. Bowlby $(1969,1973)$ found that the quality of this relationship was particularly evident at times of stress, such as when students are in a conflict, experiencing difficult emotions and not listening to authority or following rules. Students who have not experienced good enough parenting will not manage these situations calmly and will find it difficult to feel safe or trust the situation or adult. Instead they will get angry and walk away.

Many of these students came from families who were not well-educated and left school without qualifications. They had bad experiences at school and were very negative. For generations their families had experienced economic and social deprivation and exclusion. Many had experienced domestic abuse, substance misuse, poverty, jail and bereavement. They felt excluded and angry at society. 


\section{Aim}

The aim was to provide the students with a group and counsellor to help students think about their emotional and behavioural difficulties that impacted on their school life. A support network was constructed for the students by including their teachers, families, carers and professionals from outside agencies. It is imperative, when working with 'hard to reach' students, that adults keep in contact with each other to talk about their experience of these students. In this way, students are most likely to receive the most appropriate support to improve their academic achievements and their relationships with others. Various interventions were used to engage with these students to discover the barriers that might be preventing them from achieving their full academic potential.

\section{Inclusion Group}

One of these interventions was a counselling group, which was intended as a first step in changing this vicious cycle. By giving these students the opportunity to talk about their experiences it was thought that they would find it easier to stay in school. The group was mixed boys and girls from different ethnic backgrounds. They met once a week, for one hour during school time.

In the group students did talk about how they felt about school and home. They also explored how their behaviour might impact on their schoolwork and their relationships with teachers and investigated what triggers their negative behaviour. This process gave them tools for managing and resolving conflict with teachers and family members by practising in the group. The group also provided an opportunity for the counsellor to observe and experience how teachers in the class might experience these students. This then enabled the counsellor to help the students to start making changes to their behaviour by feeding back how their behaviour was experienced in the moment and working on finding different ways to communicate and learning how to share their feelings with teachers.

\section{Project Outcomes}

As the group developed and the students began to trust each other, they shared more personal stories about their families and lives outside of school. They came to realise that they shared similar worries and concerns and were not alone with their problems. They also reported that they found the group very helpful and felt comforted by other student's sharing similar concerns and feelings, which helped them feel less alone. They particularly felt relieved when they discovered that other students also shared the same concerns and problems as themselves.

Almost all students made very good use of the interventions. There was a significant reduction of incident reports and only three exclusions since the group started. There was a clear reduction in truancy and an increase in attendance, academic achievement and improved relationships with staff and other students.

\section{Further Interventions}

The counsellor also acted as a mediator between teachers and students, helping teachers to think about different ways of managing difficult behaviour and understand why students might be 'misbehaving'.

Ideally it would have been useful parents and carers to be included more in the process but this was a task that the school needed to take up. There appeared to be a resistance from the school possibly because these families were also very challenging to work with. If it is possible to include parents in the process there is a better chance of change for the students.

To 'maintain the loop' teachers met with the counsellor to discuss progress, possible further support needed and the level of behaviour expected from the student if they are to continue receiving education. It is important that student from chaotic family backgrounds have the experience of teachers and counsellors working together for their benefit. It is also important that students can trust that the counsellor will keep confidentiality and sustain their therapeutic relationship.

\section{Supporting Teachers towards Understanding}

Schools are committed to educating students and helping them to reach their full academic attainment. It is quite common particularly when students reach their teenage years that their capacity to learn is interrupted because they 
experience emotional and or social problems which are displayed through inappropriate behavioural such as smoking cigarettes/marijuana, lack of motivation and disturbing the learning of others, negative about learning, a disregard for rules using their phones in front of staff, not listening or following teachers instructions and not contributing positively to school or the wider community.

Students' attitude to school and learning can be improved if teachers are able to have a healthy curiosity and understanding about their students and what might be going on in their lives outside of school that is leading to them to exhibiting challenging behaviour such as worried or angry about something going on at home or at school, relationship problems with friends and/or family members, not meeting families expectations, concerns about growing up and the future, going to University and moving away from family to a new school or country.

\section{How can Teachers hold in mind Academic Targets and be more Child Centred?}

In 2007 a programme was designed to provide teachers with the skills, knowledge and attitude to work within a more child-centred approach (Bomber 2007), with students between the age of 11-16, who were experiencing emotional, behavioural and social problems.

One of the primary needs of students is to feel emotionally secure and to have an adult who is able to 'hold them in mind' (Winnicott 1964). Being considered by another person is a fundamental developmental need. Having another person who is able to help make sense of one's challenging behaviour and put words to feelings is crucial. Without this attention it is very difficult to engage in learning. Adolescence is a time to experiment with challenging the authority of adults, develop independence and revise and/or reject former ideas. Through these turbulent times, students need the reassurance of an adult who can lay down firm boundaries and be consistent with them.

The aim of the programme was to provide teachers with some emotional literacy for the classroom to create a more understanding culture rather than getting into conflicts with students and throwing them out of class. The programme also acknowledges that it is important that students follow the rules and teachers provide students with boundaries but that teachers also try to understand why it might be difficult for particular students to follow rules and not listen to authority. It is also helpful if teachers are able to illustrate alternative ways of handling conflict and challenging behaviour and be open to wondering out loud about how they might be feeling and put words to these feelings.

The programme also provided knowledge of child development and theory such as attachment difficulties and how trauma and loss can affect a child's ability to learn (Bowlby 1973). Patrick Casements thoughts and theories around 'the internal supervisor' would also be introduced and the capacity to learn from our mistakes and experience reparation when working with young people (Casement 2003, 2002). It is important for teachers to be non-judgemental, reflective, empathic, able to listen, thoughtful, respectful and to work hard to understand how it feels to be a student.

The best training takes place in schools throughout the day-to-day work. Schools are lively environments full of a variety of people all contributing to school life. This can be an ideal place to learn from each other, contribute as a team and to share good practice with each other. With all this richness, the school did have resources available, both inside and outside, to support them with these difficult students that would reduce the pressure and stress. If they did they would not have to just rely on the counselling service.

Teachers also need support. A Strategy Group for teachers to think about practical ways of managing difficult behaviour together and a Support Group where issues with students can be shared would not only help teachers but would also help students in difficulty. It might also be helpful to set up a group for parents to enable them to share their experiences and difficulties with their children. The group could also be a place where they could offer help and support to each other.

\section{Creating a Collaborative Understanding}

(Crowther 2003) A culture is growing in schools 'to do something' rather than try to understand how these changes might be affecting teachers and students. Teachers have resorted to a more authoritarian role that has created a more punishing culture. This need to do something is driven by anxiety, which in times of stress can inhibit teachers' ability to think (Smith 2010) and understand what the more challenging and vulnerable students might be experiencing, especially if the student is also anxious. When people are stressed it is very difficult to listen to each other and think about what the other might need and to be supportive.

These schools either punished students or referred them to the counselling service, creating a good and bad split (Hinshelwood 1994) in the school. I wondered whether there was a more collaborative way for the teachers and the 
counselling service to work together to create a supportive team around the school and student and to ensure that external influences did not prevent students from feeling included in education and reaching their potential.

In 2008 the author designed and setup an Inclusion Panel in one of the secondary schools in Sussex. The panel consisted of professionals from both inside and outside the school. It included teachers, the counsellor, educational psychologist, school nurse, neighbourhood youth worker, heads of year, pastoral assistants and the educational welfare officer. This panel provided the school with a diverse resource of professionals to work with their more challenging students.

One of the unique aspects of the panel was that it met regularly, created a more coherent and collaborative team that could confidentially discuss each student's needs and monitor their progress. Teachers worked hard to understand and support students who were causing concern rather than just excluding them from school and enforcing a punishment. Instead together they created a safety net of support around the students.

The experience was that if a team of professionals can think and work collaboratively together on a student's behalf then the student could feel understood and cared for. We found that this shifts their attitude to learning and increases their ability study as is demonstrated in the following case study.

\section{Case Study}

The following is a Case Study that demonstrates how the Inclusion Panel collaborated to ensure that a student received the appropriate support to enable her to stay in school and improve her self-esteem.

The student, Amanda, a 13 year old, was referred to the panel by the assistant head, who had a history of dealing with her sisters and had no success with keeping them in school. He was also very concerned that Amanda was at risk of repeating this family pattern of being permanently excluded. She regularly truanted from school, had difficulty controlling her anger and was struggling to sustain healthy relationships.

Amanda is the youngest of four girls who have all been permanently excluded from school. Her sisters also truanted and displayed antisocial behaviour both in school and in the wider community. Her parents left school with no qualifications and did not support the school or the idea of their daughters needing to leave school with qualifications.

When the Inclusion Panel met, teachers and various professionals shared their experience of Amanda both at school and home. This provided the team with a picture of the whole child, rather than only the badly behaved child. Once the information had been shared the Inclusion Panel then identified what support Amanda would need.

The team referred her to counselling so that Amanda had a confidential place to talk about her struggle with being unable to engage in learning while also sustaining her 'bad girl' image and acceptance from her peer group. She felt that the school did not care about her and experienced staff as being negative towards her because of how her sisters behaved in school.

The Educational Welfare Officer was also assigned to monitor her truanting from school and to liaise with the family if she did not turn up to school. Her Head of Year and Pastoral Support Assistant worked hard to build a positive relationship with Amanda's family, so that the family could begin to experience school as a place that could support Amanda and the family, rather than fight with it.

Her teachers were made aware that Amanda had shared that she wanted to change but felt that she was tarred by her older sisters' bad attitude and behaviour in the school. The teachers were helped by the counsellor to recognise what might act as a trigger for Amanda when she misbehaved in class. We discovered that quite often it was because she did not understand and felt embarrassed to ask the teacher.

\section{Professional Safety Network}

A safety net was created for Amanda through networking and collaborating with teachers and other professionals. It provided her with the experience of adults working together and thinking about her, possibly for the first time in her life. During lessons Amanda regularly took up leadership roles, such as organising a trip to theme park and co-ordinating a recycling project in the school. The deputy head, who had referred Amanda, told the Inclusion Panel that he had seen big improvement in her attitude to learning and her maths skills. Her attendance, behaviour and grades also improved. After addressing her emotional needs Amanda was able to embrace education rather than reject it, providing her with a sense of achievement and good self-esteem. 


\section{Outcome of the Work}

If professionals are able to network and collaborate with each other, they can create a safety network for students so that staff will have a better chance of helping students, like Amanda, to stay in school and work towards reaching their full potential.

\section{Impact of Pressures and Changes on the Counselling Service}

Every year more teachers are experiencing and seeing the benefits of students attending counselling so the waiting list for counselling has increased so students are having to wait for longer periods of time to see a counsellor. There has also been an increase in students presenting with mental health issues, depression, thoughts of suicide, severe anxiety and self-harm. Because of the severity of the referred problems, this sometimes means that the counsellor needs to work for longer with these students, which further extends the waiting list. The counselling service has also seen an increase in the number of students being referred with psychosomatic symptoms such as panic attacks, physical illnesses and pain.

\section{Trainee Counsellor Placement Programme}

As a way of adapting and managing the increasing number of young people being referred to counselling and so that students could see a counsellor as quickly as possible, a trainee counselling placement programme was introduced. This has been running for the past four years and has not only offered support to the school and students but also to the senior counsellor. Both the senior counsellor and manager of the service were responsible for offering the trainee counsellors trainee opportunities and fortnightly supervision.

\section{Trainee Support through Supervision}

Supervision is a word that is often used for management of staff but in this context it describes a place for counsellors to meet to talk about their work as required by our professional bodies. Supervision also provides the opportunity to develop counselling skills and knowledge and is also a space for thinking about each student's emotional needs and identifying any additional needs that could be addressed by professionals either inside or outside of the school. We then work very closely with these professionals to form a wider safety net for these students. At both of the schools, the trainee counsellors attend supervision fortnightly in a group.

\section{Supervision for teachers}

Working with vulnerable and challenging students and their families can be very difficult as it often means dealing with other people's problems and anxieties. There have been times when teachers have approached me with a concern for a student but their judgement has been clouded because the situation they have been asked to deal with is similar to what is going on in their own lives (Plant\&Smith 2009). These teachers have reported that they found it very helpful having someone to talk to confidentially to get some clarity about dealing with their concern around the young person. This has led me to start discussions about providing supervision for teachers or other professionals that work with students with schools and the therapeutic service.

\section{Creating a Culture of Support}

Although there are counselling services for individual students or groups of students, there is something important about working in developing a culture in a school where the teachers also actively contribute to developing students' emotional wellbeing and self-esteem. Teachers can really make a difference in the lives of their students.

According to the Department for Education and Skills (DfES), schools are one of the main possible sources of ensuring emotional wellbeing and resilience in children particularly for those who have experienced difficulties in their lives. The West needs to think about changing their quick fix culture of punishment and to encourage the persistence and resilience in ourselves that we want these students to have. 


\section{Conclusion}

This paper demonstrates the importance of providing supportive spaces for understanding within the school context to ensure that students achieve their full potential. It is possible that similar support mechanisms could be provided with good effect within the Albanian context.

As in the UK, it seems that classrooms are filling up with an increasing numbers of distressed children that leave teachers feeling disempowered and de-skilled as they attempt to teach. Tension rises, stress increases and unfortunately many good teachers leave the profession as a result. Every student wants to be understood but this can be difficult for teachers to hold on to (Bomber 2007). The intention would be for trainee teachers to join a supervision group and to equip them with the skills, knowledge and attitudes necessary to understand and support students who are experiencing emotional, social and academic difficulties to fulfil their potential and have a successful future. The supervision process is a way of:

- Enhancing each trainee's interpersonal skills so they have more emotional resources available to them in the classroom

- Supporting each trainees with putting child development theory into practice so they can test out what they are learning and get informed feedback from the supervisor and fellow trainees

- Supporting trainees with any challenges that inevitably arise in their school placements

- Enabling feedback from schools to be shared with trainees so they can learn from it.

- Providing them with the emotional literacy to understand how students might be feeling and also behaviour management techniques.

- Offering the possibility of exploring organisational (school setting) problems and learning about school systems, protocols and policies

The supervision process would facilitate good working relationships between the schools, the training college and the trainee teachers. It would also enhance teaching skills, increase confidence and promote safe practice for the schools, students and trainee teachers.

Following a discussion with Mr Ahmet, Director at Beder University, an idea was floated that trainee teachers in Albania might benefit from supervision/mentoring programme based on the ten years experience of this author.

\section{References}

Bomber, L., (2007). Inside I'm Hurting. Worth Publishing, London

Bowlby, J., (1969). Attachment (Volume 1 of Attachment and Loss). Hogarth Press, London

Bowlby, J., (1973). Separation: Anxiety and Anger (Volume 11 of Attachment and Loss). Hogarth Press, London

Casement, P., (1985). On Learning from the Patient. Tavistock Publications Ltd, London

Casement, P., (2002). Learning from our Mistakes. Routledge, Sussex

Cowther, C., (2003). Supervision in Institutions. Palgrave Macmillian, London

Hinshelwood, R.D., (1994). Clinical Klein. Free Associations Books, London

Obholzer, A \& Roberts, V., (1994). The Unconscious at Work. Routledge, London

Plant, R \& Smith, M., (2009). Countertransference and Parallel Process in supervision Groups. The Journal of the British Association for Psychoanalytic Supervision. Spring

Smith, M., (2010). Supervision as a Space for Thinking about the Social Defences that Impact on the Therapeutic work. In Supervision Review, Summer

Winnicott, D. W., (1964). The Child, The Famiy and the Outside World. Penguin Group, London

von Sommaruga, S., (2006). Including Hard to Reach Students. In house report for Wandsworth Council, London 